\title{
Effect of Vitronectin Bound to Insulin-Like Growth Factor-I and Insulin-Like Growth Factor Binding Protein-3 on Porcine Enamel Organ-Derived Epithelial Cells
}

\author{
Yoshinori Shinohara, ${ }^{1}$ Shuhei Tsuchiya, ${ }^{1,2}$ Kazuo Hatae, ${ }^{3}$ and Masaki J. Honda ${ }^{1,2,4}$ \\ ${ }^{1}$ Division of Stem Cell Engineering, Institute of Medical Science, The University of Tokyo, Minato-ku, \\ Tokyo 108-8639, Japan \\ ${ }^{2}$ Department of Anatomy, Nihon University School of Dentistry, Chiyoda-ku, Tokyo 101-8310, Japan \\ ${ }^{3}$ COREFRONT Corporation, Shinjuku-ku, 160-0008 Tokyo, Japan \\ ${ }^{4}$ Division of Functional Morphology, Dental Research Center, Chiyoda-ku, Tokyo 101-8310, Japan \\ Correspondence should be addressed to Masaki J. Honda, honda.masaki@nihon-u.ac.jp
}

Received 5 November 2011; Accepted 17 January 2012

Academic Editor: Petros Papagerakis

Copyright ( $) 2012$ Yoshinori Shinohara et al. This is an open access article distributed under the Creative Commons Attribution License, which permits unrestricted use, distribution, and reproduction in any medium, provided the original work is properly cited.

\begin{abstract}
The aim of this paper was to determine whether the interaction between IGF, IGFBP, and VN modulates the functions of porcine EOE cells. Enamel organs from 6-month-old porcine third molars were dissociated into single epithelial cells and subcultured on culture dishes pretreated with VN, IGF-I, and IGFBP-3 (IGF-IGFBP-VN complex). The subcultured EOE cells retained their capacity for ameloblast-related gene expression, as shown by semiquantitative reverse transcription-polymerase chain reaction. Amelogenin expression was detected in the subcultured EOE cells by immunostaining. The subcultured EOE cells were then seeded onto collagen sponge scaffolds in combination with fresh dental mesenchymal cells and transplanted into athymic rats. After 4 weeks, enamel-dentin-like complex structures were present in the implanted constructs. These results show that EOE cells cultured on IGF-IGFBP-VN complex differentiated into ameloblasts-like cells that were able to secrete amelogenin proteins and form enamel-like tissues in vivo. Functional assays demonstrated that the IGF/IGFBP/VN complex significantly enhanced porcine EOE cell proliferation and tissue forming capacity for enamel. This is the first study to demonstrate a functional role of the IGFIGFBP-VN complex in EOE cells. This application of the subculturing technique provides a foundation for further tooth-tissue engineering and for improving our understanding of ameloblast biology.
\end{abstract}

\section{Introduction}

A frequent dental disease is dental caries which is a specific infectious disease that results in localized dissolution and destruction of the calcified enamel and dentin in teeth. However, enamel cannot regenerate by itself, because the layer of ameloblasts that forms the enamel degenerates after the tooth crown is completed. Thus dentistry has formulated artificial materials that mimic the hardness of enamel to repair enamel loss, but this may not be the most appropriate therapy. Therefore, the development of a novel approach to engineer natural enamel to repair enamel loss is strongly desired.
The growth of enamel is a highly complex process that is tightly regulated through a number of control mechanisms. Numerous growth factors involved in enamel development have been shown to interact with components of the extracellular matrix (ECM). Growth factors can regulate proliferation, determination, and differentiation of enamellineage cell phenotypes. The interaction between the ECM and growth factors is believed to be an important modulator of enamel development. However, many of the mechanisms behind these interactions remain unclear.

The insulin-like growth factor (IGF) family consists of two growth factors, IGF-I and IGF-II, which are mitogenic peptide growth factors. They are involved in a diverse 
range of biological functions including development [1], cell proliferation and differentiation [2, 3], and DNA synthesis $[4,5]$, as well as insulin-like effects including an involvement in fat metabolism [1]. The IGF family is tightly regulated by two IGF receptors (IGF-IR and IGFIIR), six IGF binding proteins (IGFBP-1 to IGFBP-6), and multiple IGFBP proteases $[1,6,7]$. Both IGF-I and IGF-II and their corresponding receptors are expressed throughout amelogenesis in rat incisors [8]. The IGF family is associated with the secretion of enamel-related proteins in rodent teeth [9], and furthermore, IGF-I stimulates cell proliferation in Hertwig's epithelial root sheath in the mouse molar [10].

Vitronectin (VN) is a multifunctional $75 \mathrm{kDa}$ glycoprotein that is highly abundant in the blood and numerous tissues and forms a major component of the ECM [11]. VN plays an important role in diverse cellular processes, including cell migration, cell attachment, cell spreading, and hemostasis, that are mediated via $\alpha_{v}$ integrins $\left(\alpha_{v} \beta_{3}\right.$ and $\alpha_{v} \beta_{5}$ receptors which recognize an Arg-Gly-Asp [RGD] sequence) adjacent to the protein's $\mathrm{N}$-terminus [12-15]. VN is also involved in the immune defense system through its interaction with the terminal complex of complement [16]. It has been suggested that VN binds to growth factors including epidermal growth factor and fibroblast growth factor [17, 18], hepatocyte growth factor, IGF-II [19], and IGF-I (via IGFBPs) [20]. The functional significance of these interactions has been confirmed through observation of in vitro cellular responses in culture plates pretreated with $\mathrm{VN}$ and IGF $[21,22]$, and the ability of VN to modify IGF action in smooth muscle cells has also been demonstrated [12]. Subsequent studies have revealed that IGFBP-3, enhances IGF-I binding to VN by forming a heterotrimeric complex comprising of IGF-1, IGFBP-3 and VN (IGF-IGFBP-VN) $[20,23,24]$ and the complex results in enhanced functional responses [20, 21]. However, there have been no reports of this IGF-IGFBP-VN complex in the enamel-lineage cells, the enamel organ-derived epithelial (EOE) cells.

This study therefore examined whether the approach of prebinding IGF and IGFBP to VN-coated culture dishes would be effective in culturing EOE cells in order to produce enamel by tissue engineering methods. This strategy was adopted in an attempt to more accurately reflect the in vivo cellular environment (rather than an effect of IGF and IGFBP in solution) in which growth factors "captured" by ECM proteins participate in coordinated matricellular signaling [25]. The environment significantly enhanced cell proliferation and maintained the phenotype of the primary EOE cells. In addition, EOE cells cultured on IGF-IGFBP$\mathrm{VN}$-coated dishes, in combination with primary dental pulp cells, were capable of growing new enamel-like tissues. This study is one of the first studies to demonstrate the critical role of IGF-I, IGFBP-3, and VN on EOE cells.

\section{Materials and Methods}

2.1. Isolation and Subculture of Porcine EOE Cells. EOE cells were prepared as previously described $[26,27]$. Briefly, impacted third molars were harvested from the mandibles of 6-month-old pigs. After hard tissues were disconnected from the tooth, the enamel organ was separated from the dental pulp by treatment with dispase II (Goudou Syuzei, Tokyo, Japan) and then mechanically isolated. Minced enamel organ was treated with collagenase (Wako, Osaka, Japan) in Hank's balanced salt solution (Invitrogen, Life Technologies, NY). The released cells were passed through a $70 \mu \mathrm{m}$ cell strainer (Becton Dickinson \& Co., Franklin Lakes, NJ) and were then cultured in Dulbecco's modified eagle medium (DMEM) containing 10\% fetal bovine serum (FBS; Invitrogen) under $10 \% \mathrm{CO}_{2}$ in air for 7 days.

A mixed cell population of EOE cells and dental follicle cells were observed in primary culture. Then, to isolate the epithelial cells from the mesenchymal cells, the medium was replaced with LHC-9 medium (Biofluids, Bethesda, MD) without FBS after the cell populations reached confluence [26]. The cells were cultured under $10 \% \mathrm{CO}_{2}$ for 2 weeks, during which time most of the contaminating dental follicle cells disappeared, leaving only morphologically identifiable epithelial cells. The epithelial cells were trypsinized and inoculated onto the specified culture dishes $\left(1 \times 10^{5}\right.$ cells $\left./ \mathrm{cm}^{2}\right)$. Complete minimum essential medium based on $\alpha$-MEM (Invitrogen) supplemented with 5\% FBS, insulin $(5.0 \mu \mathrm{g} / \mathrm{mL})$, transferrin $(5 \mu \mathrm{g} / \mathrm{mL})$, triiodothyronine $\left(2 \times 10^{-10} \mathrm{M}\right)$, cholera toxin $\left(1 \times 10^{-10} \mathrm{M}\right)$, hydrocortisone $(0.5 \mu \mathrm{g} / \mathrm{mL})$, epidermal growth factor $(0.1 \mu \mathrm{g} / \mathrm{mL})$, penicillin $(1000 \mathrm{U} / \mathrm{mL})$, streptomycin $(1 \mathrm{mg} / \mathrm{mL})$, and amphotericin $\mathrm{B}$ $(2.5 \mu \mathrm{g} / \mathrm{mL})$ was applied to the subsequent subcultures. The cultured cells were observed by phase-contrast microscopy on indicated days.

\subsection{Prebinding of IGF-I and IGFBP-3 to VN (IGF-IGFBP-} $V N)$. To examine the effect of IGF-IGFBP-VN on EOE cells, culture plates were pretreated overnight with $\mathrm{VN}$ ( $150 \mathrm{ng} / \mathrm{cm}^{2}$; Tissue Therapies, Brisbane, Australia) prior to the addition of growth factors including IGF-I $\left(50 \mathrm{ng} / \mathrm{cm}^{2}\right.$; Tissue Therapies) and IGFBP-3 $\left(150 \mathrm{ng} / \mathrm{cm}^{2}\right.$; Tissue Therapies), according to the protocol $[19,28]$, and each treatment was usually performed overnight at $4^{\circ} \mathrm{C}$. All reagents were prepared in serum-free medium. For comparison, either polystyrene (PS) or collagen- type- I- (Col-I-) coated dishes (Becton Dickinson \& Co.) were used to evaluate cell growth and differentiation.

2.3. Measurement of Cell Growth. The growth of 1st and 2nd passage EOE cells on IGF-IGFBP-VN-coated dishes was examined in comparison with PS, and Col-I dishes. Subcultured EOE cells were plated at a density of $5 \times 10^{3}$ cells $/ \mathrm{mL}$ into 6-well IGF-IGFBP-VN, PS and Col-I culture plates. The EOE cells in each well were counted using a WST-8 kit (Cell-counting Kit-8; Dojindo Laboratories, Kumamoto, Japan). The counting technique employed a tetrazolium salt that produced a highly water-soluble formazan dye. After 1 hour of incubation with the reagent according to the manufacturer's instructions, relative cell numbers were determined by measuring the absorbance of light at a wavelength of $450 \mathrm{~nm}$ on days 1, 10, and 25 (Model 650 Microplate reader; Bio-Rad Laboratories, Hercules, CA). The experiment on cell growth was performed in triplicate. 
Statistical analysis was performed using Mann-whitney U test with Bonferroni's correction. Data are presented as the mean \pm standard deviation for three separate experiments. A significant difference $(P<0.05)$ between paired conditions is indicated on Figures by an asterisk.

\subsection{RNA Preparation and Semiquantitative Reverse Transcrip-} tion-Polymerase Chain Reaction (RT-PCR) Analysis. Total cellular RNA was purified from primary cells in nonserum culture medium for 10 days and subcultured cells at 10 days after first passage from three samples, using TRIZOL reagent (Invitrogen) according to the manufacturer's instructions. cDNA was synthesized from $1 \mu \mathrm{g}$ of total RNA using Superscript III RNase H- (Invitrogen). Synthesized cDNA served as a template for subsequent polymerase chain reaction (PCR) amplification. PCR primers for amelogenin, ameloblastin, enamelin, matrix-metalloprotease- (MMP-) 20 , collagen type I, IGF-I, and IGF-I receptor are listed in Table 1. Amplification was performed in a PCR Thermal Cycler SP (Takara, Tokyo, Japan) for 25-35 cycles according to the following reaction profile: $95^{\circ} \mathrm{C}$ for $30 \mathrm{~s}, 45-60^{\circ} \mathrm{C}$ for $30 \mathrm{~s}$, and $72^{\circ} \mathrm{C}$ for $30 \mathrm{~s}$. Porcine $\beta$-actin primer was used as an internal standard.

2.5. Immunocytochemistry. We tested whether the EOE cells at second passages differentiated into ameloblast-lineage cells in the IGF-IGFBP-VN or Col-I dishes. EOE cells, grown for 10 days on coverslips, were fixed in $4 \%$ paraformaldehyde for $10 \mathrm{~min}$ at room temperature and then treated with $0.1 \%$ Triton X-100 (Sigma-Aldrich, St. Louis, MO) for $5 \mathrm{~min}$ to render them permeable. The cells were then incubated with the $4 \%$ horse serum diluted in 0.01 MPBS. After blocking, the cells were incubated for $60 \mathrm{~min}$ in affinity-purified rabbit anti-pig amelogenin polyclonal antibody (1:100 dilution; a gift from Dr. J. P. Simmer, University of Michigan, Ann Arbor, MI) as an ameloblast marker. FITC-conjugated goat anti-rabbit IgG (ICN Pharmaceuticals, Inc., Aurora, OH) was then applied for $60 \mathrm{~min}$ at room temperature. The stained cells were sealed with Vectashield mounting medium containing DPAI (Dojindo) diluted 1:2000. Nonimmune rabbit serum was used to replace primary antibody as a fluorescence control.

2.6. Preparation of Collagen Sponge Scaffolds. Based on our previous results, collagen sponges were selected as scaffolds for our in vivo study (product number: CL025-PH56f/ FD90H48-02F26; a gift from NIPRO Corporation, Osaka, Japan). The performance of collagen sponge has been shown to be superior to that of polyglycolic acid fiber mesh [29]. Briefly, scaffolds approximately $10 \mathrm{~mm}$ in diameter and $2 \mathrm{~mm}$ in thickness were prepared from a $2.5 \%$ aqueous solution of collagen extracted from porcine skin. They contained $75 \%$ (dry weight) type I atelocollagen and 25\% type III atelocollagen and were frozen at $-40^{\circ} \mathrm{C}$ and vacuumdried to produce a porous matrix (pore volume fraction, $97.5 \%)$.
2.7. Enamel-Tissue Engineering Using a Combination of EOE Progenitor Cells and Dental Pulp Cells In Vivo. All experiments involving the use of animals were approved by the Institutional Animal Care and Use Committees of the Institute of Medical Science at the University of Tokyo, Japan.

Previously, we established a method to generate enamel based on a cell-scaffold construct followed by transplantation in vivo. To determine whether EOE cells subcultured using IGF-IGFBP-VN culture dishes have the potential to generate enamel tissues, we used our transplantation experiment. Primary dental pulp cells were obtained from impacted third molar teeth in the mandibles of 6-month-old pigs. After hard tissues were discarded from the tooth, only dental pulp was disconnected from the enamel organ by treatment with dispase II (Goudou Syuzei, Tokyo, Japan) and then the pulp core in the center of the dental pulp was mechanically isolated to prevent contamination of the dental follicle. Minced pulp core was treated with collagenase (Wako) in Hank's balanced salt solution (Invitrogen) for $30 \mathrm{~min}$ at $37^{\circ} \mathrm{C}$. The released cells were passed through a $70 \mu \mathrm{m}$ cell strainer (Becton Dickinson \& Co.).

The cell-seeding technique involving the combination of high densities of subcultured EOE cells with high densities of primary dental pulp cells has been described previously [30]. A high density of primary dental pulp cells ( $30 \mu \mathrm{L}$ of $5.0 \times$ $10^{6}$ cells $/ \mathrm{mL}$ ) was first placed on top of the collagen sponges and incubated for $1 \mathrm{~h}$. Subsequently, a high density of EOE cells at day 10 of cultivation $\left(30 \mu \mathrm{L}\right.$ of $5 \times 10^{6}$ cells $\left./ \mathrm{mL}\right)$ after 1 passage was seeded directly on top of the dental pulp cells. The subcultured EOE cells were allowed to adhere onto the dental pulp cells for an additional hour. In the control group, oral keratinocytes obtained from the oral mucosa of 6-month-old pig mandibular jaws were subcultured and seeded at high density on the top of the dental pulp cells after the primary dental pulp cells had been seeded onto the collagen sponges $(n=3)$. The scaffolds with cells were then transplanted into the omentum of immunodeficient rats aged 5-7 weeks (F344/n Jcl-rnu, Nihoncrea, Japan) $(n=3)$. The omentum was sutured to prevent movement of the test and control implants [31-33]. The implants were allowed to develop for 4 weeks after which time they were fixed in Bouin's solution and demineralized in 30\% EDTA and then embedded in paraffin. $5 \mu \mathrm{m}$ sections were cut and stained with hematoxylin and eosin for histological analysis.

Since epithelium and pulp tissues are tightly connected, there is a high chance of contamination. This was monitored by observation with phase contrast microscopy and RT-PCR using the cultivation of dental pulp cells. This confirmation has been used in our previous studies [34, 35].

2.8. Immunohistochemistry. Immunohistochemical analyses were performed on paraffin-embedded tissue sections with a Vectastain ABC kit (Vector Laboratories, Inc., Burlingame) using affinity-purified rabbit anti-pig amelogenin polyclonal antibody (1:2000 dilution, gift from Dr Simmer, University of Michigan, USA) as the primary antibody. Standard procedures [36] were modified as described in detail by Chen et al. [37]. 
TABLE 1: Sequence of primer pairs used for semiquantitative RT-PCR.

\begin{tabular}{|c|c|c|c|c|c|}
\hline Gene & & Sequence & $\begin{array}{c}\text { Annealing temperature } \\
\left({ }^{\circ} \mathrm{C}\right)\end{array}$ & $\begin{array}{l}\text { Amplicon } \\
\text { (bp) }\end{array}$ & $\begin{array}{c}\text { Accession number or } \\
\text { reference }\end{array}$ \\
\hline \multirow{2}{*}{ Amelogenin } & Forward & 5-CCTGCCTTTTGGGAGCA & \multirow{2}{*}{50} & \multirow{2}{*}{328} & \multirow{2}{*}{ NM213800 } \\
\hline & Reverse & 5-TGGTGGTGTTGGGTTGGA & & & \\
\hline \multirow{2}{*}{ Ameloblastin } & Forward & 5-ATTCCCAACCTGGCAAGAGG & \multirow{2}{*}{55} & \multirow{2}{*}{380} & \multirow{2}{*}{ NM214037 } \\
\hline & Reverse & 5-AGCGCTTTTAATGCCTTTGC & & & \\
\hline \multirow{2}{*}{ Enamelin } & Forward & 5-TGAGGAGATGATGCGCTATG & \multirow{2}{*}{45} & \multirow{2}{*}{315} & \multirow{2}{*}{ NM214241 } \\
\hline & Reverse & 5-TGAGGTGTCTGGGTTTCCTC & & & \\
\hline \multirow{2}{*}{ Enamelysin } & Forward & 5-ATACGTGCAGCGAATAGATGC & \multirow{2}{*}{45} & \multirow{2}{*}{290} & \multirow{2}{*}{ NM213905 } \\
\hline & Reverse & 5-CTATTTAGCAACCAATCCAGG & & & \\
\hline \multirow{2}{*}{ Collagen type I } & Forward & 5-GATCCTGCTGACGTGGCCAT & \multirow{2}{*}{55} & \multirow{2}{*}{212} & \multirow{2}{*}{ AY350905 } \\
\hline & Reverse & 5-ACTCGTGCAGCCGTCGTAGA & & & \\
\hline \multirow{2}{*}{ IGF-I } & Forward & 5-GACGCTCTTCAGTTCGTGTG & \multirow{2}{*}{50} & \multirow{2}{*}{348} & \multirow{2}{*}{ NM214256 } \\
\hline & Reverse & 5-ACTCGTGCAGAGCAAAGGAT & & & \\
\hline \multirow{2}{*}{ IGF-IR } & Forward & 5-ACTGTATGGTGGCCGAAGAC & \multirow{2}{*}{50} & \multirow{2}{*}{391} & \multirow{2}{*}{ NM214172 } \\
\hline & Reverse & 5-ATCTCGTCCTTGATGCTGCT & & & \\
\hline \multirow{2}{*}{ beta-actin } & Forward & 5-TCGACCACAGGGTAGGTTTC & \multirow{2}{*}{45} & \multirow{2}{*}{497} & \multirow{2}{*}{ AF017079 } \\
\hline & Reverse & 5-CCCCAGCATCAAAGGTAGAA & & & \\
\hline
\end{tabular}

\section{Results}

3.1. Effect of IGF-IGFBP-VN on EOE Cell Growth. EOE cells were easily obtained from explant culture, but the culture was a mixed population (Figure 1(a)). After replacing the serumcontaining medium with nonserum medium, the dental follicle cells disappeared and only the EOE cells were left. The EOE cells showed the cobblestone morphology that is typical of epithelial cells (Figure 1(b)). However the EOE cells did not grow in the nonserum medium, so selected EOE cells were then plated onto the IGF-IGFBP-VN-coated dishes (passage 1) and after four days of subculture, several small colonies of EOE cells appeared (Figure 1(c)). The colonies increased with time and became confluent after 25 days of cultivation and were then subcultured as passage 2 (Figure $1(d)$ ). Both groups of passaged cells showed the typical polygonal-shaped epithelial morphology. EOE cells were also cultured onto PS (Figure 1(d)) and Col-I-coated dishes (passage 1) (Figure 1(e)); however, the EOE cells displayed an extended morphology. In addition, EOE cells could not be grown on either PS or Col-I dishes after the second passage.

We compared the rate of cell proliferation of EOE cells that were cultured on the IGF-IGFBP-VN, Col-I, and PS culture dishes at passage 1 (Figure 2). We found that EOE cells grew at similar rates on the IGF-IGFBP-VN and Col-I culture dishes until day 10 of cultivation, but the cells exhibited a much lower proliferation rate at day 25 of cultivation when cultured on the Col-I dishes. There was a significant difference $(P<0.05)$ at day 25 between the growth rates in these different culture conditions. Interestingly, EOE cells did not grow on the PS dishes.

3.2. Differentiation of EOE Cells. We studied whether the EOE cells would be able to differentiate into ameloblasts. RT-PCR was used to examine the expression of various ameloblast-related genes (Table 1) in the EOE cells. The EOE cells, grown in LHC-9 as primary culture cells, expressed mRNA for amelogenin, ameloblastin, enamelin, MMP-20, IGF-I, IGF-I receptor (IGF-IR), and collagen type I. After subculture at passage 1, expression of amelogenin and MMP20 was not detected in the PS culture though some expression of ameloblastin and enamelin was detected (Figure 3). The expression pattern of the ameloblast-related genes of the EOE cells in the Col-I culture was similar to that of the IGFIGFBP-VN culture. Interestingly, mRNA of amelogenin in the IGF-IGFBP-VN culture was more highly expressed than that in the Col-I culture. In addition, expression of IGF-I and IGF-IR mRNA was higher in the IGF-IGFBP-VN culture than that in the Col-I culture. Collagen type I gene was not detected in any of the cultures at passage 1 (Figure 3 ).

Using immunocytochemistry, we next examined the protein expression of amelogenin to determine whether the EOE cells were differentiated into ameloblasts. Amelogenin expression was detected in the EOE cells in both the Col-I (Figures 4(a) and 4(b)) and IGF-IGFBP-VN cultures (Figures $4(\mathrm{c}), 4(\mathrm{~d})$, and $4(\mathrm{e}))$ after 14 days cultivation at passage 1. The degree of expression in the IGF-IGFBP-VN culture was higher than that of the Col-I culture. There was no expression of amelogenin in the EOE cells under PS culture conditions (data not shown).

3.3. Histology of the Tissue-Engineered Enamel-Dentin Complexes. We examined the enamel-forming capability of the EOE cells by transplanting seeded collagen sponges into the omentum of athymic rats. These in vivo experiments were performed 3 times for a transplantation period and obtained consistent data at the time period examined.

At four weeks after transplantation, the implants from the scaffolds seeded with both cultured EOE cells and fresh dental pulp cells revealed hard tissue formation (Figure 5(a)). At this time, the scaffolds were already 


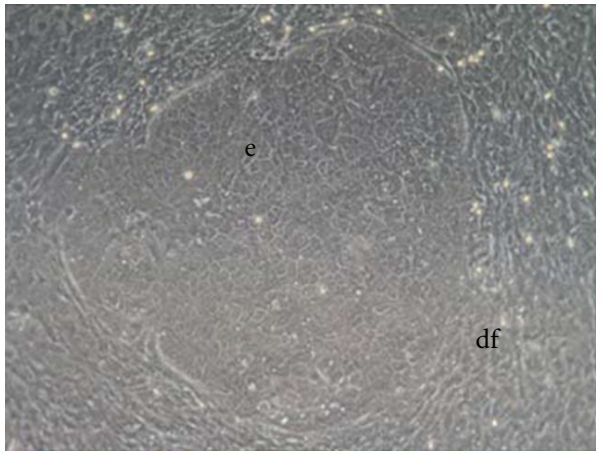

(a)

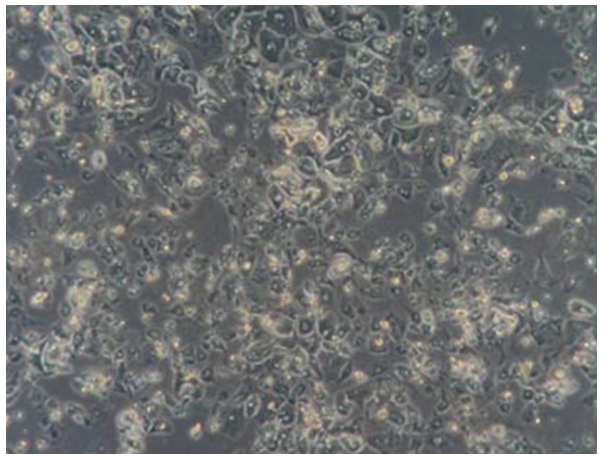

(c)

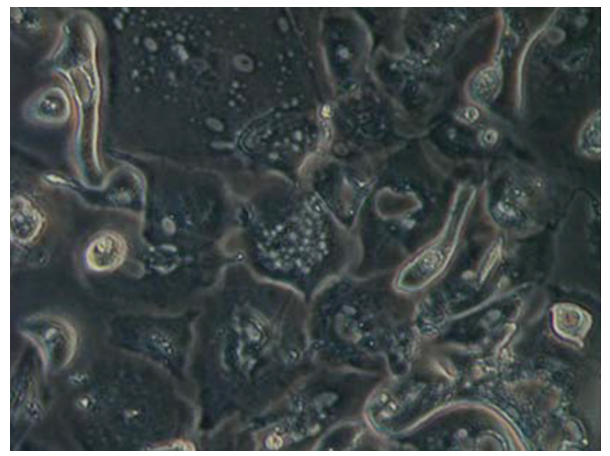

(e)

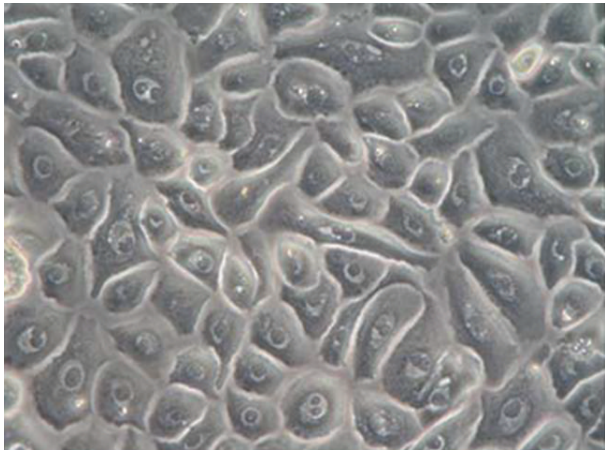

(b)

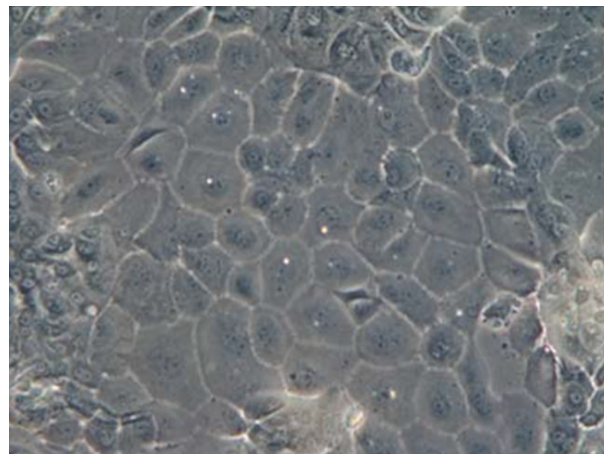

(d)

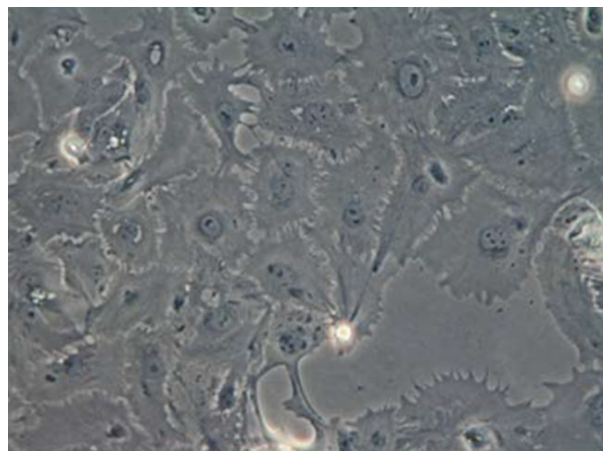

(f)

FIgure 1: Phase-contrast micrographs. (a) Mixed culture of enamel organ-derived epithelial (EOE) cells and dental follicle cells after 1 week of culture. The epithelial cells (e) have formed an island within the strongly proliferating dental follicle cells (df). (b) EOE cells in LHC9 medium. After replacing the serum-medium with LHC-9, only EOE cells survived in the nonserum medium. The colony of EOE cells showed a cobblestone appearance associated with typical epithelial morphology. (c) Subcultured EOE cells (passage 1) grown on the insulinlike growth factor-I/insulin-like growth factor binding protein-3/vitronectin complex after 10 days of cultivation. (d) EOE cells cultured on insulin-like growth factor-I/insulin-like growth factor binding protein-3/vitronectin (IGF-IGFBP-VN) complex. After 1 passaged, EOE cells had the same characteristic morphology. After 25 days of cultivation, the colony became confluent. The EOE cells had the same characteristic morphology. (e) EOE cells cultured on collagen type I-coated dishes. The cells showed a vague outline and expanded morphology. (f) EOE cells cultured on PS. The EOE cells displayed on extended morphology. Scale bars: $100 \mu \mathrm{m}(\mathrm{a}), 50 \mu \mathrm{m}$ (b-d) length.

degraded and not visible in the implants. The developmental stage of amelogenesis was recognized in one implant at this stage. Enamel organ-like structures and enamel-dentin complex-like structures were recognized in the implants from the scaffolds seeded with both cultured EOE cells and fresh dental papilla cells by histological analysis (Figures 5(b) and 5(c)). In hematoxylin-eosin stained sections, at high magnification, enamel-like tissue was easily found inside the dentin-like tissue generated in the implants (Figure 5(d)). At higher magnification, the width of the dentin-like tissue was approximately $50 \mu \mathrm{m}$. The tall columnar ameloblast-like cells were aligned with the surface of the thin enamel-like tissues. The nuclei of the ameloblasts were localized at the edge of the cells most distal to the epithelial cells. At this stage, dentin tubules were clearly identified in the enameldentin-like complex (Figure 5(e)). 


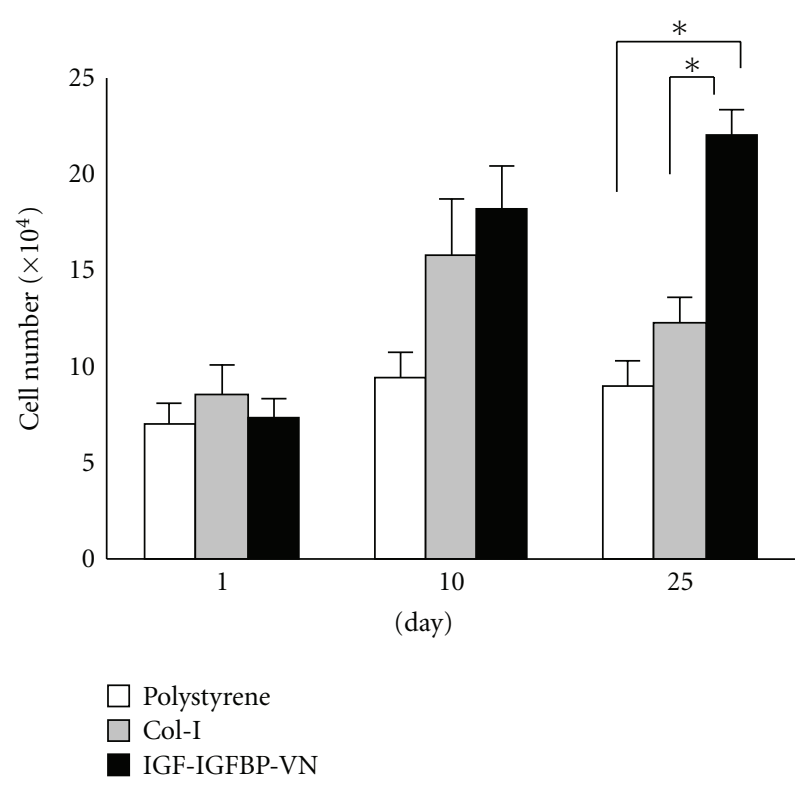

Figure 2: Comparison of the cell proliferation of enamel organderived epithelial (EOE) cells on polystyrene, collagen type I, and insulin-like growth factor-I/insulin-like growth factor binding protein-3/vitronectin (IGF-IGFBP-VN) complex at passage 1 . The number of cells was counted on days 1,10 , and 25 . The growth of EOE cells on IGF-IGFBP-VN complex was faster than that of EOE cells on Col-I. The EOE cells did not grow on PS. Asterisks indicate a significant difference $(P<0.05)$ between paired conditions.

Immunohistochemistry was used to examine the distribution of amelogenin in the implants at 4 weeks after transplantation. Amelogenin expression was present in the enamel-like tissue and ameloblast-like cells, while the ameloblast-like cells without enamel formation stained negative for amelogenin (Figure 5(f)).

\section{Discussion}

This study reports a new in vitro culture technique for EOE cells using a complex of IGF-I, IGFBP-3, and VN. We have demonstrated the potential use of this IGFIGFBP-VN complex in the manufacture of bioengineered enamel through the transplantation assay of EOE cells, but some interaction with dental mesenchymal cells is required for enamel generation. Four weeks after transplantation, enamel was produced on the surface of the dentin after dentin formation. During the enamel formation process, the presence of components of the enamel organ, such as the cells resembling stellate reticulum, inner enamel epithelium, and ameloblasts, appeared to mimic the course of normal enamel development. On the other hand, after the propagation of EOE cells in vitro, EOE cells were differentiated into preameloblasts or ameloblasts associated with ameloblastrelated gene and protein expressions. The characterization of stem/progenitor cells includes the capacity for both selfrenewal and differentiation. Based on our in vitro and in vivo research, we have demonstrated that cultured EOE cells using

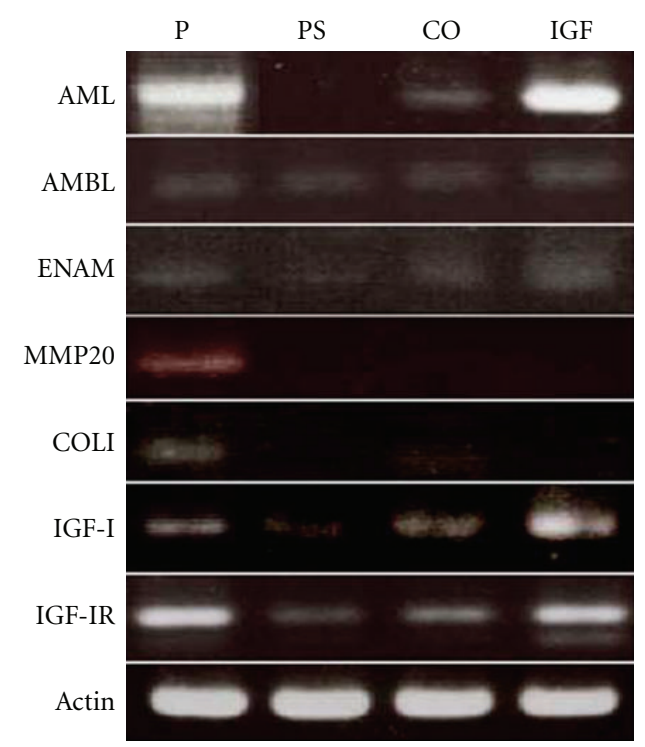

FIGURE 3: Semiquantitative reverse transcription-polymerase chain reaction analysis of enamel organ-derived epithelial (EOE) cells cultured on insulin-like growth factor-I/insulin-like growth factor binding protein-3/vitronectin complex (IGF) in comparison with the mixed cells from the primary culture (P), and EOE cells on polystyrene (PS) and collagen- type-I-(Co)- coated dishes. Amelogenin (AML), ameloblastin (AMBL), enamelin (ENAM), matrix metalloprotease-20 (enamelysin, MMP20), collagen I (COLI), insulin-like growth factor-I (IGF-I), insulin-like growth factor I receptor (IGF-IR), and beta-actin (Actin) in cultured EOE cells were examined. Primary cells (P) expressed all the examined genes. Cultured EOE cells at passage 1 on PS expressed ameloblastin and enamelin. The expression pattern in the IGF culture was similar to that of the CO culture. Both IGF-I and IGF-IR were more strongly expressed in IGF compared to CO.

IGF-IGFBP-VN include the cells with stem/progenitor characteristics. However, further analysis is needed to examine the precisely developmental stage of EOE cells.

Our previous approach solved the main obstacle to propagation of EOE cells in vitro by using a feeder layer of cells [27]. Cultured EOE cells, under a feeder layer, in combination with dental papilla cells formed enameldentin complexes in our in vivo experiments. As a control, we examined the potential of oral keratinocytes to form enamel by using the same methods, but there was no enamel formation in the implants in vivo. This was the first report of enamel-tissue engineering using cultured EOE cells. Although the approach of using a feeder layer has proven to be a major advance $[38,39]$, the method is quite complicated and there is the possibility that the cells in the feeder layer may turn cancerous because immortalized 3T3J2 cells are used as the feeder layer [39]. Thus, a new approach to propagate EOE cells without feeder cells was desirable. Interestingly, the period required for enamel generation by our approach using IGF-IGFBP-VN was similar to that of using a feeder layer [34]. Since the source of the dental pulp cells for combination with the scaffold is the same [34], these results suggest that the potential of this new technique 


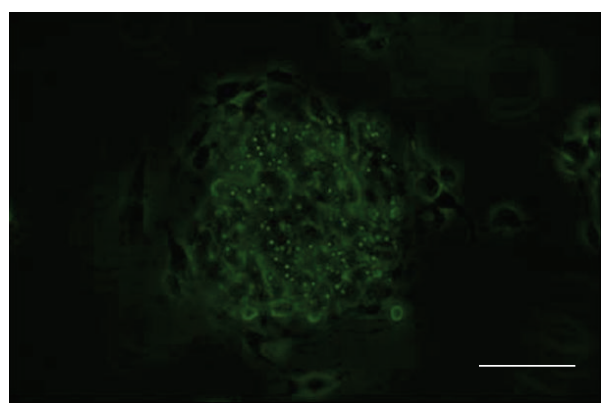

(a)

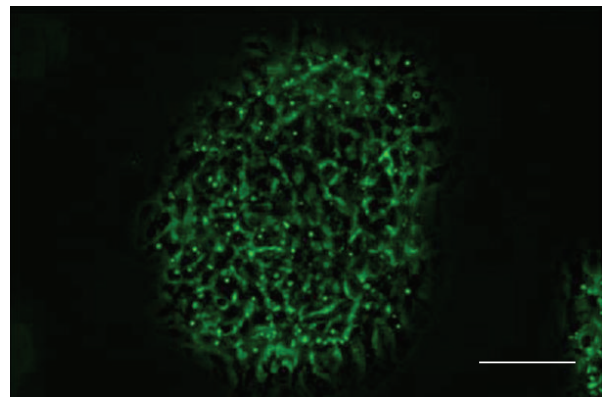

(c)

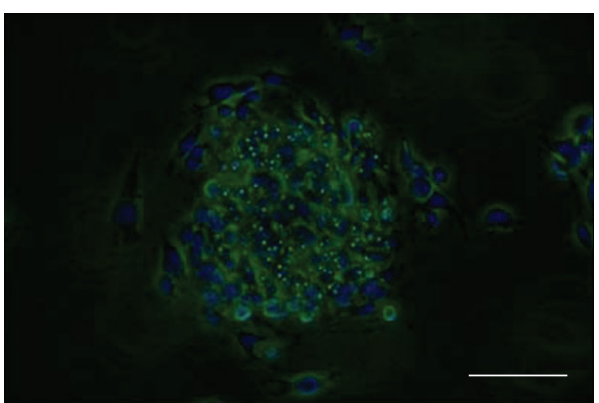

(b)

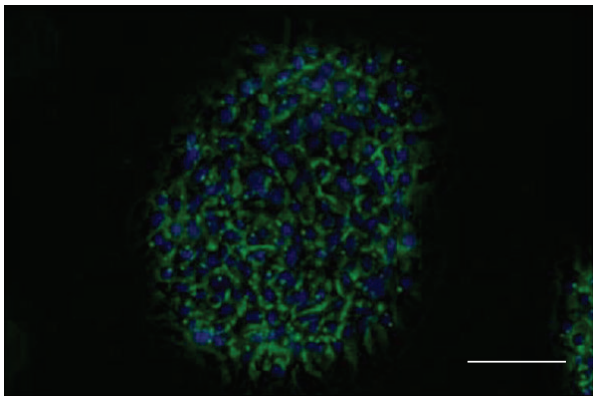

(d)

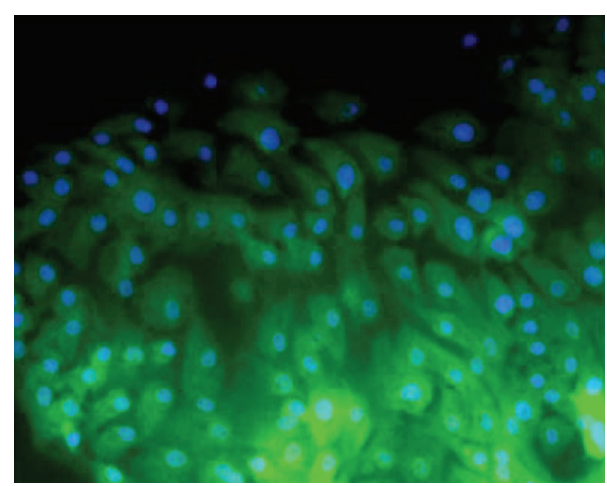

(e)

FIGURE 4: Immunofluorescence analysis in enamel organ-derived epithelial (EOE) cells. (a) Immunofluorescence showed that EOE cells were positive for amelogenin in the collagen type I-coated dishes. (b) Merged image to (a). Amelogenin staining in combination with DAPI to stain DNA (blue). (c) EOE cells were positive for amelogenin by immunofluorescence in the insulin-like growth factor-I/insulin-like growth factor binding protein-3/vitronectin complex-coated dishes. The staining of amelogenin in the EOE cells was more intense than that in the collagen type I-coated dishes. (d) Merged image to (c). Amelogenin staining in combination with DAPI to stain DNA (blue). Scale bars: $50 \mu \mathrm{m}$ length $(\mathrm{a}-\mathrm{d})$. (e) The high magnification view of (d). EOE cells cultured on in the insulin-like growth factor-I/insulin-like growth factor binding protein-3/vitronectin complex-coated dishes expressed strongly amelogenin.

using the IGF-IGFBP-VN complex is similar to that of the technique using a feeder layer of cells.

How does the IGF-IGFBP-VN complex work in the EOE cells? Although our results indicated that IGF-I and IGF receptor expression was observed in the EOE cells in all culture conditions, interestingly, the EOE cells in the IGFIGFBP-VN culture dishes highly expressed IGF-I and the IGF-I receptor, which indicated that the activity could be increased by autocrine or paracrine signals. Little is known about the effects of VN on EOE cells although an increasing number of functions are being discovered for VN. The molecule is best known for its actions on cell attachment and spreading $[16,40]$. In a study of epithelial cells, it was demonstrated that VN has an effect on the metabolic activity of cultured corneal-limbal epithelial cells [23] and skin keratinocytes [28]. It is therefore not surprising that the cellular activity of EOE cells was enhanced by VN.

It is well known that IGF-I is a potent mitogen involved in normal growth and development [1] and influences cell division and differentiation $[41,42]$. IGFs are also recognized as having important roles in tooth development; addition of exogenous IGF-I to molar teeth maintained in culture 


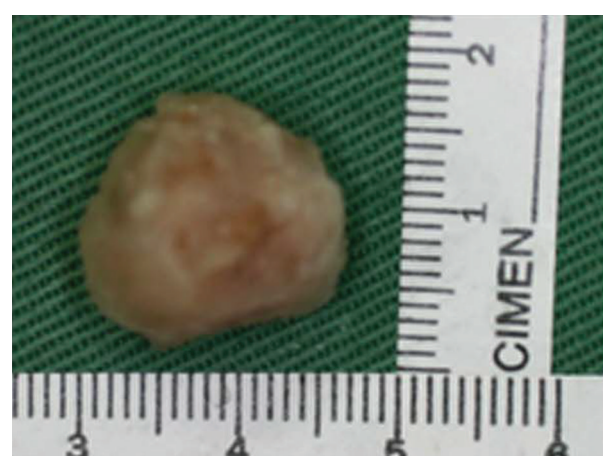

(a)

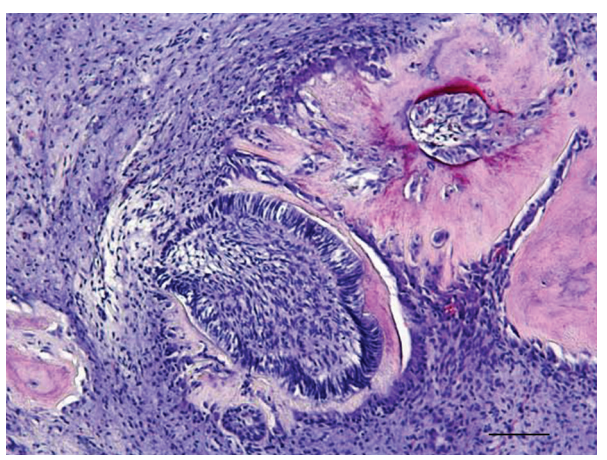

(c)

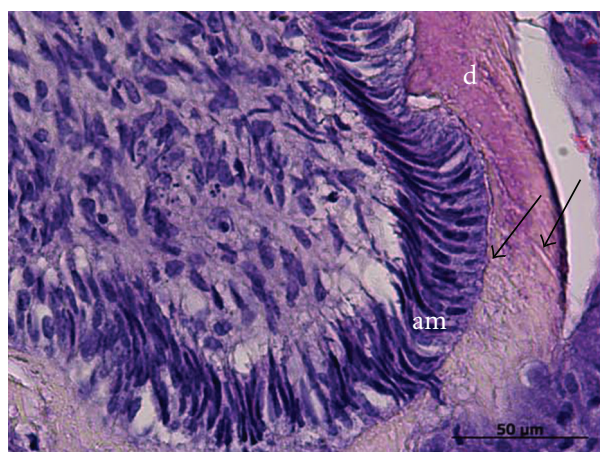

(e)

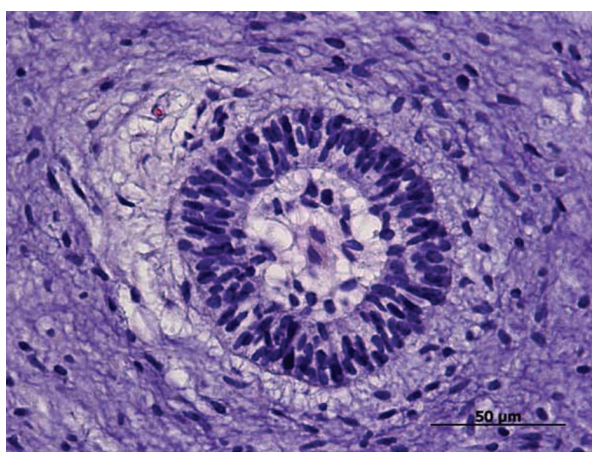

(b)

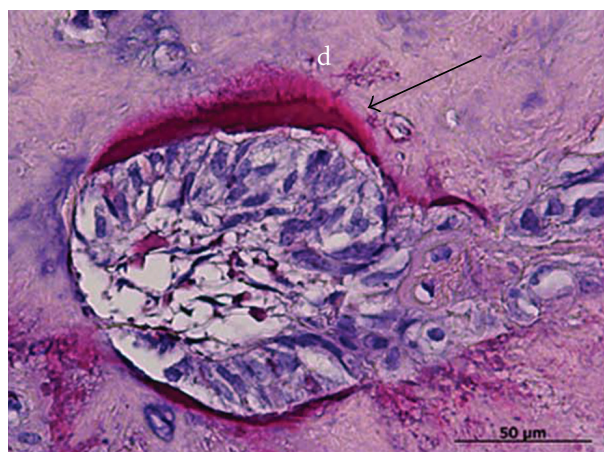

(d)

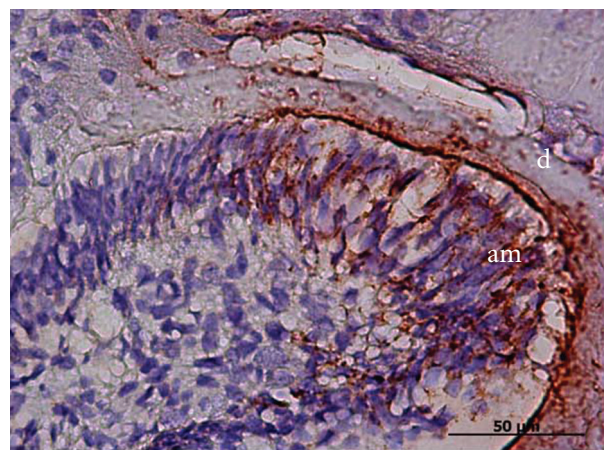

(f)

FIGURE 5: The implants at four weeks after transplantation. (a) Round-shaped implants were produced by the constructs formed between cultured enamel organ-derived epithelial (EOE) cells and dental pulp cells in a scaffold. (b) An enamel organ-like structure associated with an epithelial cell cluster was seen in the implant. Columnar cells were organized in a circle and dental pulp cells embraced the enamel organ. (c) Enamel-like tissue formation on the surface of the dentin, stained with hematoxylin-eosin. (d) High magnification of (c), showing that enamel-like tissue (black arrow) stained with eosin was strongly displayed in the implant. (e) High magnification of (c), showing that tall columnar ameloblast-like cells (am) were aligned perpendicular to the dentin-like tissues (d). (f) High magnification of (c), showing that amelogenin expression was strongly identified in the enamel-like tissue adjacent to the dentin-like tissues and ameloblast-like cells. Scale bars: $50 \mu \mathrm{m}$ (b, d-f), $200 \mu \mathrm{m}$ (c) length.

results in an increase in tooth volume [43]. In organ cultures of mouse molars, exogenous administration of IGFI increases the synthesis of amelogenin, ameloblastin, and enamelin [44]. These results suggest that IGF-I promotes differentiation and development of ameloblasts. The IGFI receptor has also been identified in the enamel organ across amelogenesis [8]. Moreover, IGF-I appears to be effective in promoting proliferation of Hertwig's epithelial root sheath [10]. Thus, IGF and its receptors are involved in the growth of the epithelium as the tooth develops, including the stages of crown and root formation. In our study, the expression of IGF-I was dramatically increased in EOE cells in culture with the IGF-IGFBP-VN complex. The significance of the IGF-IGFBP-VN complex has been confirmed through observation of other cellular responses in culture plates pretreated with VN, IGF-I, and IGFBP-3 $[21,22]$. This is the first study to demonstrate that the IGFIGFBP-VN complex can enhance the proliferation activity 
associated with the maintenance of the phenotype of EOE cells. Although IGF-IGFBP-VN plays critical functions in the cell cycle, the exact mechanism by which IGF-IGFBP-VN facilitates cell proliferation remains unclear. Recently, there is accumulating evidence for direct cooperation between the IGF-I receptor and $\alpha_{v}$-integrins as the signaling pathways between these receptors are clearly interconnected $[45,46]$. Furthermore, IGF-I-IGFBP-VN complexes induce synergistic increases in intracellular signal transduction, in particular, an increased and sustained activation of the phosphatidylinositol 3-kinase/AKT pathway [25]. Through the IGF-I receptor, IGF-I can activate multiple signaling pathways, including the phosphatidylinositol 3-kinase and mitogen-activated protein kinase pathways in tumor cells [47]. Facilitation of the cell cycles may accelerate tissue development, however further studies will be required to clarify this issue.

To develop a protocol for enamel-tissue engineering, an appropriate culture method is required to obtain a sufficient number of stem/progenitor cells. The present study revealed that the IGF-IGFBP-VN complex provides a viable alternative to the feeder layer technique. Nevertheless, there is room for refinement of this technology, including extended serial propagation studies, the use of alternative markers of differentiated ameloblasts and formed enamel, and further optimization of the IGF-IGFBP-VN complex formulation to increase the formation of enamel.

\section{Acknowledgments}

The authors thank Dr. J. P. Simmer for generously providing the amelogenin antibodies. This work was supported in part by grants from the Japanese Ministry of Education, Culture, Sports, Science and Technology (Kakenhi Kiban B 21390528 and Houga 20659305 to M. J. Honda) and by a grant from Dental Research Center, Nihon University School of Dentistry.

\section{References}

[1] T. L. Wood, "Gene-targeting and transgenic approaches to IGF and IGF binding protein function," American Journal of Physiology, vol. 269, no. 4, pp. E613-E622, 1995.

[2] S. Adi, B. Bin-Abbas, N. Y. Wu, and S. M. Rosenthal, "Early stimulation and late inhibition of extracellular signalregulated kinase $1 / 2$ phosphorylation by IGF-I: a potential mechanism mediating the switch in IGF-I action on skeletal muscle cell differentiation," Endocrinology, vol. 143, no. 2, pp. 511-516, 2002.

[3] W. S. Cohick and D. R. Clemmons, "The insulin-like growth factors," Annual Review of Physiology, vol. 55, pp. 131-153, 1993.

[4] L. A. Bach, "The insulin-like growth factor system: basic and clinical aspects," Australian and New Zealand Journal of Medicine, vol. 29, no. 3, pp. 355-361, 1999.

[5] W. Kiess, Y. Yang, U. Kessler, and A. Hoeflich, "Insulinlike growth factor II (IGF-II) and the IGF-II/mannose-6phosphate receptor: the myth continues," Hormone Research, vol. 41, supplement 2, pp. 66-73, 1994.

[6] R. C. Baxter, "Insulin-like growth factor (IGF)-binding proteins: interactions with IGFs and intrinsic bioactivities,"
American Journal of Physiology, vol. 278, no. 6, pp. E967-E976, 2000.

[7] D. R. Clemmons, "Role of insulin-like growth factor binding proteins in controlling IGF actions," Molecular and Cellular Endocrinology, vol. 140, no. 1-2, pp. 19-24, 1998.

[8] T. Yamamoto, S. Oida, and T. Inage, "Gene expression and localization of insulin-like growth factors and their receptors throughout amelogenesis in rat incisors," Journal of Histochemistry and Cytochemistry, vol. 54, no. 2, pp. 243-252, 2006.

[9] W. G. Young, J. V. Ruch, M. R. Stevens et al., "Comparison of the effects of growth hormone, insulin-like growth factor-I and fetal calf serum on mouse molar odontogenesis in vitro," Archives of Oral Biology, vol. 40, no. 9, pp. 789-799, 1995.

[10] N. Fujiwara, M. J. Tabata, M. Endoh, K. Ishizeki, and T. Nawa, "Insulin-like growth factor-I stimulates cell proliferation in the outer layer of Hertwig's epithelial root sheath and elongation of the tooth root in mouse molars in vitro," Cell and Tissue Research, vol. 320, no. 1, pp. 69-75, 2005.

[11] T. Nogita and M. Kawashima, "Increased levels of plasma vitronectin in severe psoriatic patients," Archives of Dermatological Research, vol. 284, no. 5, pp. 315-317, 1992.

[12] D. R. Clemmons, G. Horvitz, W. Engleman, T. Nichols, A. Moralez, and G. A. Nickols, "Synthetic $\alpha \mathrm{V} \beta 3$ antagonists inhibit insulin-like growth factor-I-stimulated smooth muscle cell migration and replication," Endocrinology, vol. 140, no. 10, pp. 4616-4621, 1999.

[13] X. Huang, J. Wu, S. Spong, and D. Sheppard, "The integrin $\alpha \mathrm{V} \beta 6$ is critical for keratinocyte migration on both its known ligand, fibronectin, and on vitronectin," Journal of cell science, vol. 111, part 15, pp. 2189-2195, 1998.

[14] H. S. Kim, S. R. Nagalla, Y. Oh, E. Wilson, C. T. Roberts Jr., and R. G. Rosenfeld, "Identification of a family of lowaffinity insulin-like growth factor binding proteins (IGFBPs): characterization of connective tissue growth factor as a member of the IGFBP superfamily," Proceedings of the National Academy of Sciences of the United States of America, vol. 94, no. 24, pp. 12981-12986, 1997.

[15] R. Pytela, M. D. Pierschbacher, and E. Ruoslahti, "A 125/115$\mathrm{kDa}$ cell surface receptor specific for vitronectin interacts with the arginine-glycine-aspartic acid adhesion sequence derived from fibronectin," Proceedings of the National Academy of Sciences of the United States of America, vol. 82, no. 17, pp. 5766-5770, 1985.

[16] I. Schvartz, D. Seger, and S. Shaltiel, "Vitronectin," International Journal of Biochemistry and Cell Biology, vol. 31, no. 5, pp. 539-544, 1999.

[17] S. Rahman, Y. Patel, J. Murray et al., "Novel hepatocyte growth factor (HGF) binding domains on fibronectin and vitronectin coordinate a distinct and amplified Met-integrin induced signalling pathway in endothelial cells," BMC Cell Biology, vol. 6, article 8, 2005.

[18] M. Schoppet, T. Chavakis, N. Al-Fakhri, S. M. Kanse, and K. T. Preissner, "Molecular interactions and functional interference between vitronectin and transforming growth factor- $\beta$," Laboratory Investigation, vol. 82, no. 1, pp. 37-46, 2002.

[19] Z. Upton, H. Webb, K. Hale et al., "Identification of vitronectin as a novel insulin-like growth factor-II binding protein," Endocrinology, vol. 140, no. 6, pp. 2928-2931, 1999.

[20] J. A. Kricker, C. L. Towne, S. M. Firth, A. C. Herington, and Z. Upton, "Structural and functional evidence for the interaction of insulin-like growth factors (IGFs) and IGF binding proteins with vitronectin," Endocrinology, vol. 144, no. 7, pp. $2807-$ 2815, 2003. 
[21] N. A. M. Taek, A. Moralez, and D. Clemmons, "Vitronectin binding to IGF binding protein-5 (IGFBP-5) alters IGFBP-5 modulation of IGF-I actions," Endocrinology, vol. 143, no. 1, pp. 30-36, 2002.

[22] A. Noble, C. Towne, L. Chopin, D. Leavesley, and Z. Upton, "Insulin-like growth factor-II bound to vitronectin enhances MCF-7 breast cancer cell migration," Endocrinology, vol. 144, no. 6, pp. 2417-2424, 2003.

[23] S. L. Ainscough, Z. Barnard, Z. Upton, and D. G. Harkin, "Vitronectin supports migratory responses of corneal epithelial cells to substrate bound IGF-I and HGF, and facilitates serumfree cultivation," Experimental Eye Research, vol. 83, no. 6, pp. 1505-1514, 2006.

[24] B. Hollier, D. G. Harkin, D. Leavesley, and Z. Upton, "Responses of keratinocytes to substrate-bound vitronectin: growth factor complexes," Experimental Cell Research, vol. 305, no. 1, pp. 221-232, 2005.

[25] B. G. Hollier, J. A. Kricker, D. R. Van Lonkhuyzen, D. I. Leavesley, and Z. Upton, "Substrate-bound insulin-like growth factor (IGF)-I-IGF binding protein-vitronectin-stimulated breast cell migration is enhanced by coactivation of the phosphatidylinositide 3-kinase/AKT pathway by $\alpha \mathrm{v}$-integrins and the IGF-I receptor," Endocrinology, vol. 149, no. 3, pp. 1075-1090, 2008.

[26] P. K. Den Besten, C. H. Mathews, C. Gao, and W. Li, "Primary culture and characterization of enamel organ epithelial cells," Connective Tissue Research, vol. 38, no. 1-4, pp. 3-35, 1998.

[27] M. J. Honda, T. Shimodaira, T. Ogaeri, Y. Shinohara, K. Hata, and M. Ueda, "A novel culture system for porcine odontogenic epithelial cells using a feeder layer," Archives of Oral Biology, vol. 51, no. 4, pp. 282-290, 2006.

[28] C. Hyde, B. Hollier, A. Anderson, D. Harkin, and Z. Upton, "Insulin-like growth factors (IGF) and IGF-binding proteins bound to vitronectin enhance keratinocyte protein synthesis and migration," Journal of Investigative Dermatology, vol. 122, no. 5, pp. 1198-1206, 2004.

[29] Y. Sumita, M. J. Honda, T. Ohara et al., "Performance of collagen sponge as a 3-D scaffold for tooth-tissue engineering," Biomaterials, vol. 27, no. 17, pp. 3238-3248, 2006.

[30] M. J. Honda, S. Tsuchiya, Y. Sumita, H. Sagara, and M. Ueda, "The sequential seeding of epithelial and mesenchymal cells for tissue-engineered tooth regeneration," Biomaterials, vol. 28, no. 4, pp. 680-689, 2007.

[31] M. J. Honda, Y. Shinohara, Y. Sumita, A. Tonomura, H. Kagami, and M. Ueda, "Shear stress facilitates tissue-engineered odontogenesis," Bone, vol. 39, no. 1, pp. 125-133, 2006.

[32] M. J. Honda, Y. Sumita, H. Kagami, and M. Ueda, "Histological and immunohistochemical studies of tissue engineered odontogenesis," Archives of Histology and Cytology, vol. 68, no. 2, pp. 89-101, 2005.

[33] C. S. Young, S. Terada, J. P. Vacanti, M. Honda, J. D. Bartlett, and P. C. Yelick, "Tissue engineering of complex tooth structures on biodegradable polymer scaffolds," Journal of Dental Research, vol. 81, no. 10, pp. 695-700, 2002.

[34] M. J. Honda, Y. Shinohara, K. I. Hata, and M. Ueda, "Subcultured odontogenic epithelial cells in combination with dental mesenchymal cells produce enamel-dentin-like complex structures," Cell Transplantation, vol. 16, no. 8, pp. 833-847, 2007.

[35] Y. Shinmura, S. Tsuchiya, K. I. Hata, and M. Honda, "Quiescent epithelial cell rests of malassez can differentiate into ameloblast-like cells," Journal of Cellular Physiology, vol. 217, no. 3, pp. 728-738, 2008.
[36] S. M. Hsu, L. Raine, and H. Fanger, "A comparative study of the peroxidase-antiperoxidase method and an avidin-biotin complex method for studying polypeptide hormones with radioimmunoassay antibodies," American Journal of Clinical Pathology, vol. 75, no. 5, pp. 734-738, 1981.

[37] J. K. Chen, H. S. Shapiro, J. L. Wrana, S. Reimers, J. N. Heersche, and J. Sodek, "Localization of bone sialoprotein (BSP) expression to sites of mineralized tissue formation in fetal rat tissues by in situ hybridization," Matrix, vol. 11, no. 2, pp. 133-143, 1991.

[38] J. G. Rheinwald and H. Green, "Formation of a keratinizing epithelium in culture by a cloned cell line derived from a teratoma," Cell, vol. 6, no. 3, pp. 317-330, 1975.

[39] J. G. Rheinwald and H. Green, "Serial cultivation of strains of human epidermal keratinocytes: the formation of keratinizing colonies from single cells," Cell, vol. 6, no. 3, pp. 331-334, 1975.

[40] K. T. Preissner, "Structure and biological role of vitronectin," Annual Review of Cell Biology, vol. 7, pp. 275-310, 1991.

[41] C. A. Conover, "In vitro studies of insulin-like growth factor I and bone," Growth Hormone and IGF Research, vol. 10, supplement, pp. S107-S110, 2000.

[42] A. Turnber, M. C. Meikle, and P. A. Hill, "Autocrine signals promote osteoblast survival in culture," Journal of Endocrinology, vol. 167, no. 3, pp. 383-390, 2000.

[43] J. Catón, P. Bringas Jr., and M. Zeichner-David, "IGFs increase enamel formation by inducing expression of enamel mineralizing specific genes," Archives of Oral Biology, vol. 50, no. 2, pp. 123-129, 2005.

[44] K. Takahashi, A. Yamane, P. Bringas, J. Caton, H. C. Slavkin, and M. Zeichner-David, "Induction of amelogenin and ameloblastin by insulin and insulin-like growth factors (IGF-I and IGF-II) during embryonic mouse tooth development in vitro," Connective Tissue Research, vol. 38, no. 1-4, pp. 269278, 1998.

[45] D. R. Clemmons, L. A. Maile, Y. Ling, J. Yarber, and W. H. Busby, "Role of the integrin $\alpha \mathrm{V} \beta 3$ in mediating increased smooth muscle cell responsiveness to IGF-I in response to hyperglycemic stress," Growth Hormone and IGF Research, vol. 17, no. 4, pp. 265-270, 2007.

[46] L. A. Maile, W. H. Busby, K. Sitko et al., "Insulin-like growth factor-i signaling in smooth muscle cells is regulated by ligand binding to the 177CYDMKTTC184 sequence of the $\beta 3$ subunit of $\alpha \mathrm{V} \beta 3$," Molecular Endocrinology, vol. 20, no. 2, pp. 405-413, 2006.

[47] R. O'Connor, "Regulation of IGF-I receptor signaling in tumor cells," Hormone and Metabolic Research, vol. 35, no. 1112, pp. 771-777, 2003. 


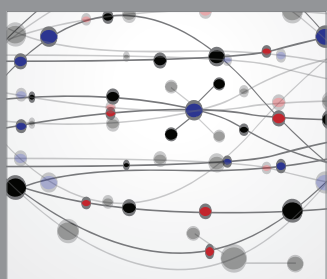

The Scientific World Journal
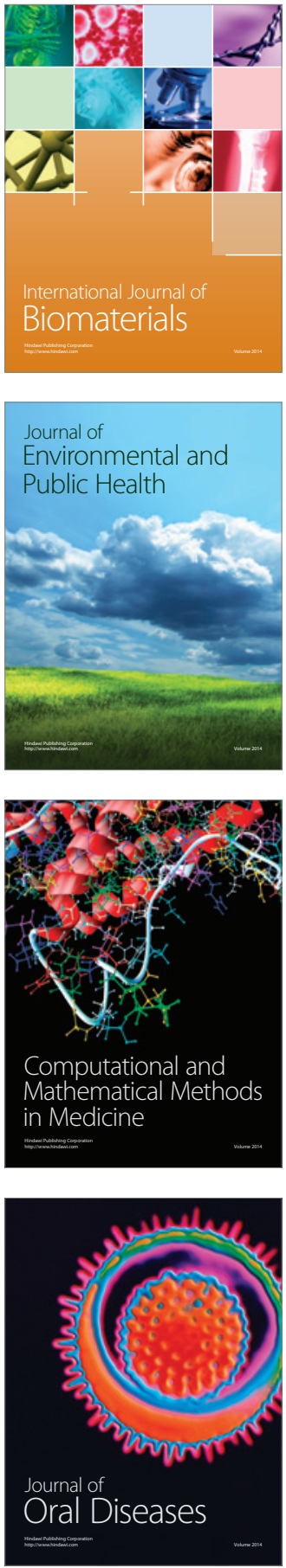
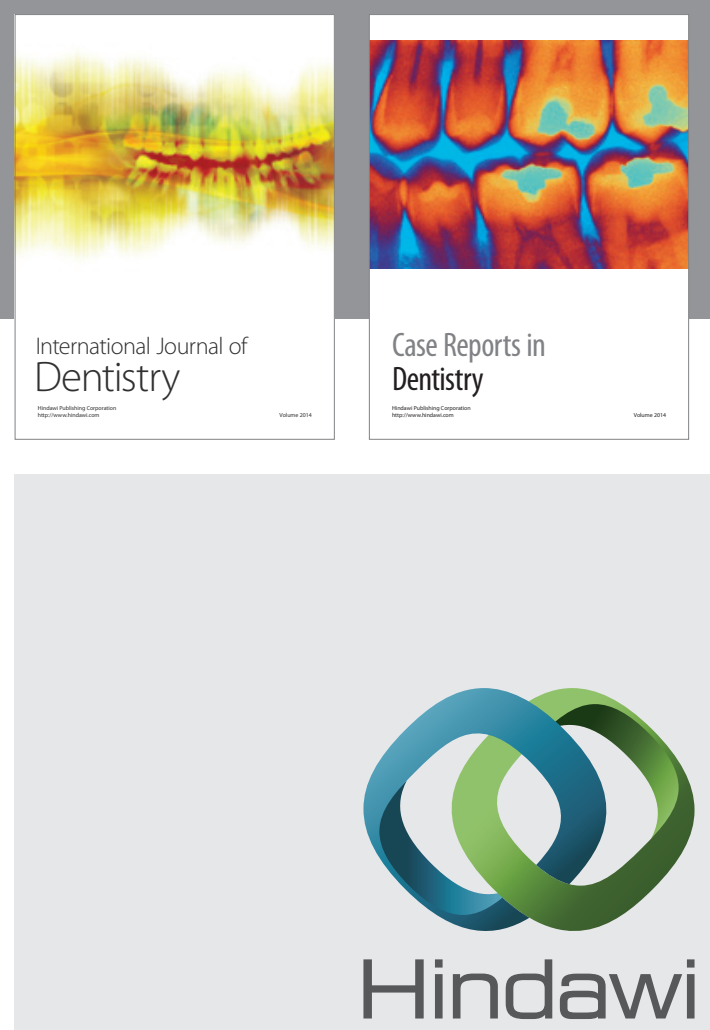

Submit your manuscripts at

http://www.hindawi.com
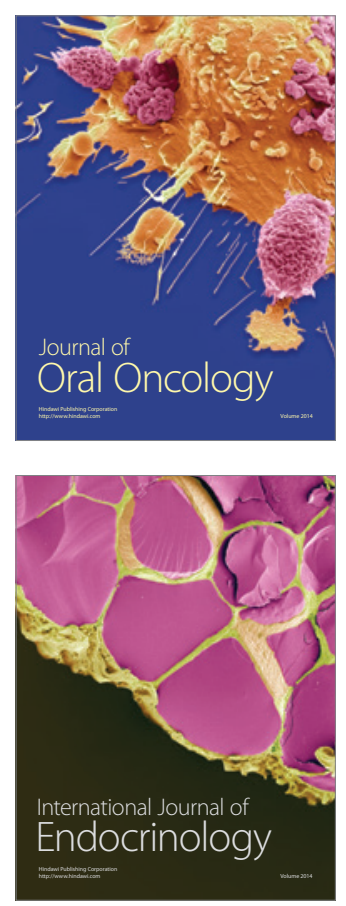
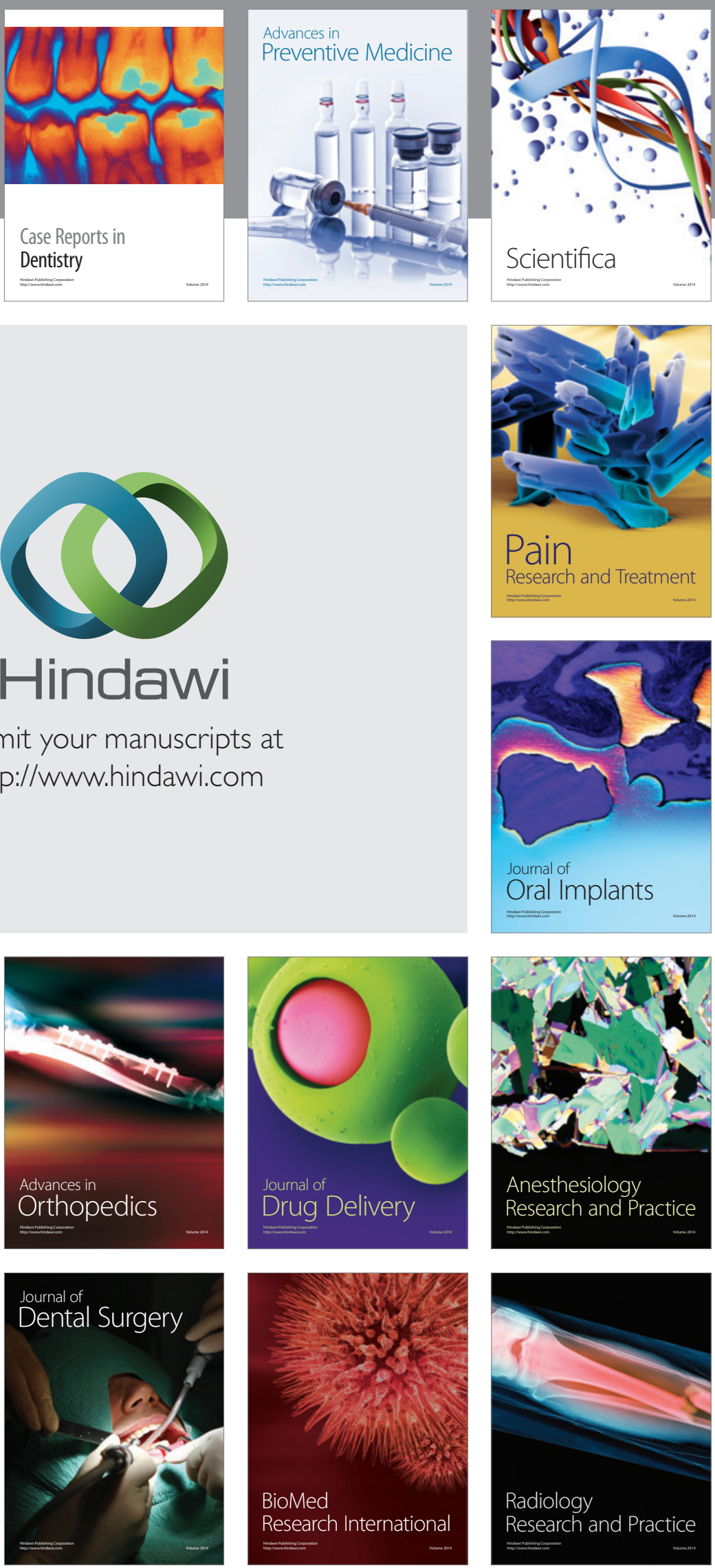